\title{
CD5-Positive Primary Intraocular B-Cell Lymphoma Arising during Methotrexate and Tumor Necrosis Factor Inhibitor Treatment
}

\author{
Kenji Nagata $^{a}$ Tohru Inaba $^{b}$ Shigeru Kinoshita ${ }^{c}$ \\ Departments of ${ }^{a}$ Ophthalmology, ${ }^{b}$ Infection Control and Laboratory Medicine, and \\ ${ }^{\mathrm{c}}$ Frontier Medical Science and Technology for Ophthalmology, Kyoto Prefectural \\ University of Medicine, Kyoto, Japan
}

\section{Key Words}

Primary intraocular lymphoma $\cdot \mathrm{CD} 5+\mathrm{B}$-cell lymphoma $\cdot$ Methotrexate $\cdot$ Tumor necrosis factor inhibitor · Epstein-Barr virus

\begin{abstract}
Purpose: To report a case of CD5+ primary intraocular B-cell lymphoma arising during methotrexate (MTX) and tumor necrosis factor (TNF) inhibitor treatment in a young patient with rheumatoid arthritis and uveitis. Case Presentation: A 39-year-old woman treated with MTX and a TNF inhibitor for rheumatoid arthritis and uveitis had steroid-resistant vitreous opacity. A vitreous sample was obtained by using diagnostic vitrectomy and was categorized as class $\mathrm{V}$ based on cytologic examination. Flow cytometric analysis of the vitreous sample revealed that abnormal cells were $\mathrm{CD} 5+, \mathrm{CD} 10-, \mathrm{CD} 19+, \mathrm{CD} 20+$ and immunoglobulin lightchain kappa+, suggesting the diagnosis of CD5+ primary intraocular B-cell lymphoma. Polymerase chain reaction (PCR) detected immunoglobulin heavy-chain gene rearrangement. Epstein-Barr virus (EBV) DNA was detected in the vitreous sample by using PCR, and immunohistochemistry revealed EBV latent membrane protein-1 expression in the abnormal cells infiltrating the vitreous. Optic nerve invasion was observed on magnetic resonance imaging. Conclusion: Primary intraocular lymphoma (PIOL) may develop in patients receiving MTX and TNF inhibitor treatment. EBV infection may play an important role in the pathogenesis of PIOL arising during immunosuppressive therapy.


Nagata et al.: CD5-Positive Primary Intraocular B-Cell Lymphoma Arising during Methotrexate and Tumor Necrosis Factor Inhibitor Treatment

\section{Introduction}

Methotrexate (MTX) is used as an anchor drug for rheumatoid arthritis (RA). A lymphoproliferative disorder (LPD), known as MTX-associated LPD (MTX-LPD), occasionally develops in patients treated with MTX $[1,2]$. Lymphoma commonly occurs in patients with MTX-LPD. In 2008, the US Food and Drug Administration reported that tumor necrosis factor (TNF) inhibitor use might be associated with a higher incidence of lymphoma. However, more recent studies have suggested that lymphoma development is associated with juvenile idiopathic arthritis or RA itself, and TNF inhibitor treatment is not associated with an increased risk of this malignancy [3]. However, the combination of TNF inhibitors and immunosuppressive agents may further increase the potential risk of malignancy.

We report the case of CD5+ primary intraocular B-cell lymphoma in a young patient with RA and uveitis who was treated with MTX and a TNF inhibitor.

\section{Case Report}

A 39-year-old female patient with RA had been undergoing treatment with MTX and a TNF inhibitor (etanercept, infliximab, or golimumab) for 10 years. She had uveitis in the right eye since 2010, for which she was treated by her own ophthalmologist. Uveitis episodes with hypopyon, posterior synechia, and severe vitreous opacity were observed occasionally, and were responsive to topical corticosteroid and subtenon triamcinolone acetonide injection. Genital ulcer and skin eruptions had appeared once. She had HLA-B51 and HLA-B27. Therefore, the etiology of uveitis was thought to be Behcet's disease, HLA-B27associated uveitis, or RA-associated uveitis. In August 2013, she presented to a former ophthalmologist with decreased vision. Ocular examination revealed a visual acuity of 0.7 in the right eye. Slit-lamp examination revealed keratic precipitate and anterior chamber cells, and fundus examination revealed vitreous opacity in the right eye. She received subtenon triamcinolone acetonide injection. However, vitreous opacity worsened, and her visual acuity decreased. Because of steroid-resistant vitreous opacity, she was referred to the Kyoto Prefectural University of Medicine Hospital in January 2014. Ocular examination revealed a visual acuity of 0.01 in the right eye. Intraocular pressure in the right eye was $14 \mathrm{~mm} \mathrm{Hg}$. Slit-lamp examination revealed neither keratic precipitate nor cells in the anterior chamber. Fundus examination revealed severe vitreous opacity in her right eye (fig. 1a). Because of severe vitreous opacity, the retinal vessels and retina could not be observed in detail. There was no abnormal finding in her left eye. She received pars plana vitrectomy, and a vitreous sample was collected during surgery. Cytologic examination of the vitreous specimen showed that more than half of the cellular component consisted of abnormal lymphoid cells (fig. 2a). They were slightly to moderately large in size with irregular-shaped nuclei, occasionally showing prominent nucleoli, but neither vacuoles nor granules were definitely found in their cytoplasm. Flow cytometric analysis revealed these abnormal cells to be positive for CD5, CD19, CD20, and immunoglobulin light-chain kappa but negative for CD10 (fig. 2b). Polymerase chain reaction (PCR) detected immunoglobulin heavy-chain gene rearrangement. Interleukin (IL)-10 and IL-6 levels in the vitreous sample were 32 and 288 $\mathrm{pg} / \mathrm{ml}$, respectively. Quantitative PCR for Epstein-Barr virus (EBV) revealed $1.09 \times 10^{7}$ cop$\mathrm{ies} / \mathrm{ml}$ in the vitreous samples and abnormal cells infiltrating the vitreous expressed EBV latent membrane protein (LMP)-1 in the vitreous cell block (fig. 2c). These findings were consistent with a diagnosis of immunosuppression-related intraocular large B-cell lymphoma. Magnetic resonance imaging revealed optic nerve invasion (fig. 1b). No other lymphoma 
Nagata et al.: CD5-Positive Primary Intraocular B-Cell Lymphoma Arising during Methotrexate and Tumor Necrosis Factor Inhibitor Treatment

lesion was detected using positron emission tomography. The patient received intravitreal MTX injection and systemic chemotherapy.

\section{Discussion}

Primary intraocular lymphoma (PIOL) is most frequently observed in elderly patients. A case of PIOL was reported in an 81-year-old woman during MTX treatment [4]. To the best of our knowledge, this is the first case of PIOL to arise during MTX and TNF inhibitor treatment in a young patient.

Latent EBV infection has been suggested to play an important role in the pathogenesis of lymphoma arising in patients receiving immunosuppressive therapy. In the present case, EBV LMP-1 expression by abnormal cells infiltrating the vitreous suggests that EBV infection is involved in the pathogenic mechanism of PIOL development during MTX and TNF inhibitor treatment.

The IL-10/IL-6 ratio in vitreous fluid from patients with PIOL is frequently greater than 1.0 [5-7]. However, in the present case, the IL-10/IL-6 ratio was less than 1.0. This can be attributed to the pre-existing uveitis, which made it difficult to diagnose PIOL via ophthalmoscopy. It has been reported that the levels of some cytokines in the vitreous fluid of uveitis patients are significantly higher than those in normal vitreous fluid $[8,9]$. Especially, the IL-6 level is elevated in the vitreous fluid of patients with uveitis. In the present case, the IL-6 level was elevated in the vitreous fluid, and the IL10/IL-6 ratio was relatively decreased. However, various types of analyses of a vitreous sample obtained by pars plana vitrectomy enabled the diagnosis of PIOL.

CD5+ diffuse large B-cell lymphoma (DLBCL) is becoming increasingly recognized as a rare and aggressive subtype of DLBCL [10]. De novo CD5+ DLBCL is seen in 5-10\% of DLBCLs [11]. However, the percentage of CD5+ DLBCLs in PIOL cases is unknown. In our experience, all intraocular B cell lymphoma cases, with the exception of the present case, have been CD5- DLBCLs. We found only one report describing CD5+ intraocular lymphoma associated with mucosa-associated lymphoid tissue lymphoma, which was different from DLBCL [12]. Older age, female sex, elevated serum lactate dehydrogenase level, highly extensive extranodal involvement, poor performance status, higher incidence of central nervous system involvement, inferior response to rituximab-containing regimens, and advanced stage have been reported to be associated with CD5+ DLBCL [13-15]. In the present case, optic nerve invasion was observed. CD5+ PIOL may present with a more aggressive clinical course. Further investigations should be performed to analyze the relationship between CD5 expression and clinical features in PIOL.

We reported a rare case of CD5+ primary intraocular B-cell lymphoma arising during MTX and TNF inhibitor treatment. Clinicians must consider the potential risk of lymphoma including intraocular lymphoma in patients who are using MTX and TNF inhibitors. The diagnosis of PIOL is difficult in patients with vitreous opacity who have pre-existing uveitis. It is important to perform diagnostic vitrectomy for treatment-resistant vitreous opacity.

\section{Acknowledgments}

This work was supported by a Grant-in-Aid for Scientific Research 00457988 from the Ministry of Education, Culture, Sports, Science, and Technology, Tokyo, Japan. We thank Mr. Katsuhiko Shinomiya for his technical support and Dr. Kazunori Takeda for collecting data. 
Nagata et al.: CD5-Positive Primary Intraocular B-Cell Lymphoma Arising during Methotrexate and Tumor Necrosis Factor Inhibitor Treatment

\section{Statement of Ethics}

The patient has consented to the submission of the case report for submission to the journal.

\section{Disclosure Statement}

The authors have no financial interest in any aspect of this report.

\section{References}

1 Mariette X, Cazals-Hatem D, Warszawki J, Liote F, Balandraud N, Sibilia J: Lymphomas in rheumatoid arthritis patients treated with methotrexate: a 3-year prospective study in France. Blood 2002;99:39093915.

-2 Hoshida Y, Xu JX, Fujita S, Nakamichi I, Ikeda J, Tomita Y, Nakatsuka S, Tamaru J, Iizuka A, Takeuchi T, Aozasa K: Lymphoproliferative disorders in rheumatoid arthritis: clinicopathological analysis of 76 cases in relation to methotrexate medication. J Rheumatol 2007;34:322-331.

3 Ruperto N, Martini A: Juvenile idiopathic arthritis and malignancy. Rheumatology (Oxford) 2014;53:968974.

-4 Rizkalla K, Rodrigues S, Proulx A, Tingey DP, Heathcote JG: Primary intraocular lymphoma arising during methotrexate treatment of temporal arteritis. Can J Ophthalmol 2005;40:585-592.

5 Chan CC, Whitcup SM, Solomon D, Nussenblatt RB: Interleukin-10 in the vitreous of patients with primary intraocular lymphoma. Am J Ophthalmol 1995;120:671-673.

6 Kimura K, Usui Y, Goto H: Clinical features and diagnostic significance of the intraocular fluid of 217 patients with intraocular lymphoma. Jpn J Ophthalmol 2012;56:383-389.

7 Whitcup SM, Stark-Vancs V, Wittes RE, Solomon D, Podgor MJ, Nussenblatt RB, Chan CC: Association of interleukin 10 in the vitreous and cerebrospinal fluid and primary central nervous system lymphoma. Arch Ophthalmol 1997;115:1157-1160.

-8 de Boer JH, van Haren MA, de Vries-Knoppert WA, Baarsma GS, de Jong PV, Postema FJ, Rademakers AJ, Kijlstra A: Analysis of IL-6 levels in human vitreous fluid obtained from uveitis patients, patients with proliferative intraocular disorders and eye bank eyes. Curr Eye Res 1992;11(suppl):181-186.

-9 Nagata K, Maruyama K, Uno K, Shinomiya K, Yoneda K, Hamuro J, Sugita S, Yoshimura T, Sonoda KH, Mochizuki M, Kinoshita S: Simultaneous analysis of multiple cytokines in the vitreous of patients with sarcoid uveitis. Invest Ophthalmol Vis Sci 2012;53:3827-3833.

10 Jain P, Fayad LE, Rosenwald A, Young KH, O’Brien S: Recent advances in de novo CD5+ diffuse large B cell lymphoma. Am J Hematol 2013;88:798-802.

-11 Harada S, Suzuki R, Uehira K, Yatabe Y, Kagami Y, Ogura M, Suzuki H, Oyama A, Kodera Y, Ueda R, Morishima Y, Nakamura S, Seto M: Molecular and immunological dissection of diffuse large B cell lymphoma: CD5+, and CD5- with CD10+ groups may constitute clinically relevant subtypes. Leukemia 1999;13:1441-1447.

12 Raparia K, Chang CC, Chevez-Barrios P: Intraocular lymphoma: diagnostic approach and immunophenotypic findings in vitrectomy specimens. Arch Pathol Lab Med 2009;133:1233-1237.

13 Yamaguchi M, Ohno T, Oka K, Taniguchi M, Ito M, Kita K, Shiku H: De novo CD5-positive diffuse large B-cell lymphoma: clinical characteristics and therapeutic outcome. Br J Haematol 1999;105:1133-1139.

14 Niitsu N, Okamoto M, Tamaru JI, Yoshino T, Nakamura N, Nakamura S, Ohshima K, Nakamine H, Hirano M: Clinicopathologic characteristics and treatment outcome of the addition of rituximab to chemotherapy for CD5-positive in comparison with CD5-negative diffuse large B-cell lymphoma. Ann Oncol 2008;21:20692074.

15 Ennishi D, Takeuchi K, Yokoyama M, Asai H, Mishima Y, Terui Y, Takahashi S, Komatsu H, Ikeda K, Yamaguchi M, Suzuki R, Tanimoto M, Hatake K: CD5 expression is potentially predictive of poor outcome among biomarkers in patients with diffuse large B-cell lymphoma receiving rituximab plus CHOP therapy. Ann Oncol 2008;19:1921-1926. 
Case Reports in

Ophthalmology

\begin{tabular}{l|l}
\hline Case Rep Ophthalmol 2015;6:301-306 \\
\hline DOI: 10.1159/000440646 & $\begin{array}{l}\text { @ } 2015 \text { The Author(s). Published by S. Karger AG, Basel } \\
\text { www.karger.com/cop }\end{array}$
\end{tabular}

Nagata et al:: CD5-Positive Primary Intraocular B-Cell Lymphoma Arising during Methotrexate and Tumor Necrosis Factor Inhibitor Treatment
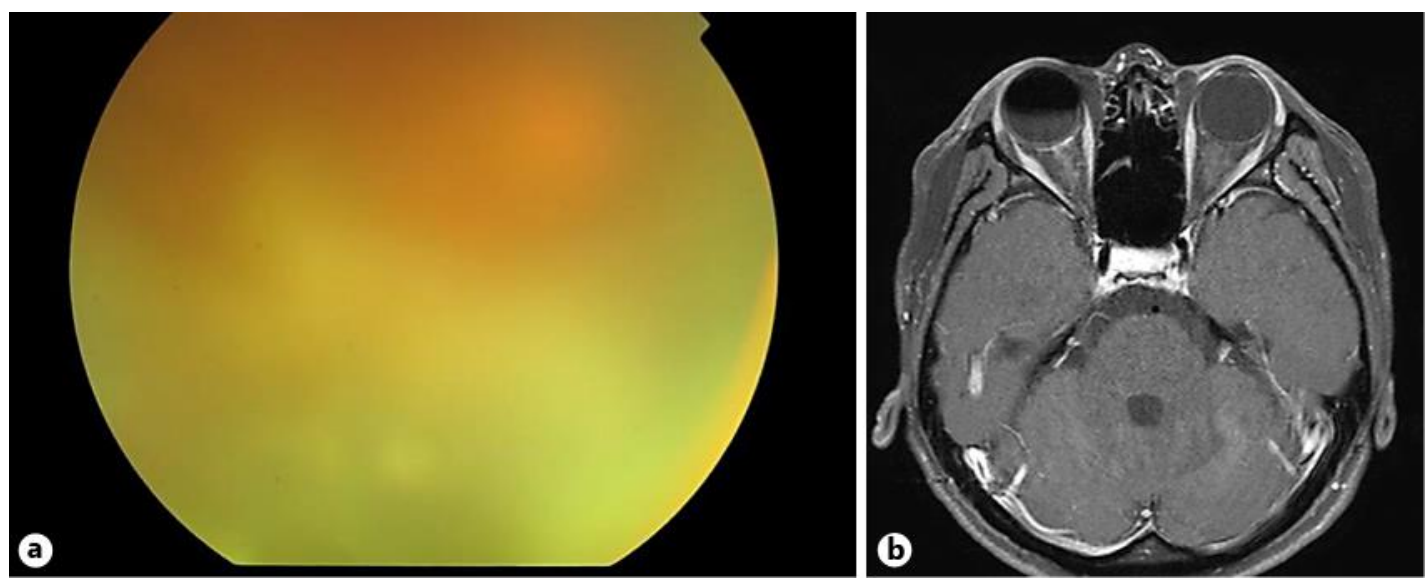

Fig. 1. Fundus findings before and during vitrectomy. a A color fundus photograph of the right eye showing severe vitreous opacity. $\mathbf{b}$ Axial gadolinium-enhanced T1-weighted magnetic resonance imaging of the brain shows enhancement of the right optic nerve. 


\section{Case Reports in \\ Ophthalmology}

Nagata et al:: CD5-Positive Primary Intraocular B-Cell Lymphoma Arising during Methotrexate and Tumor Necrosis Factor Inhibitor Treatment

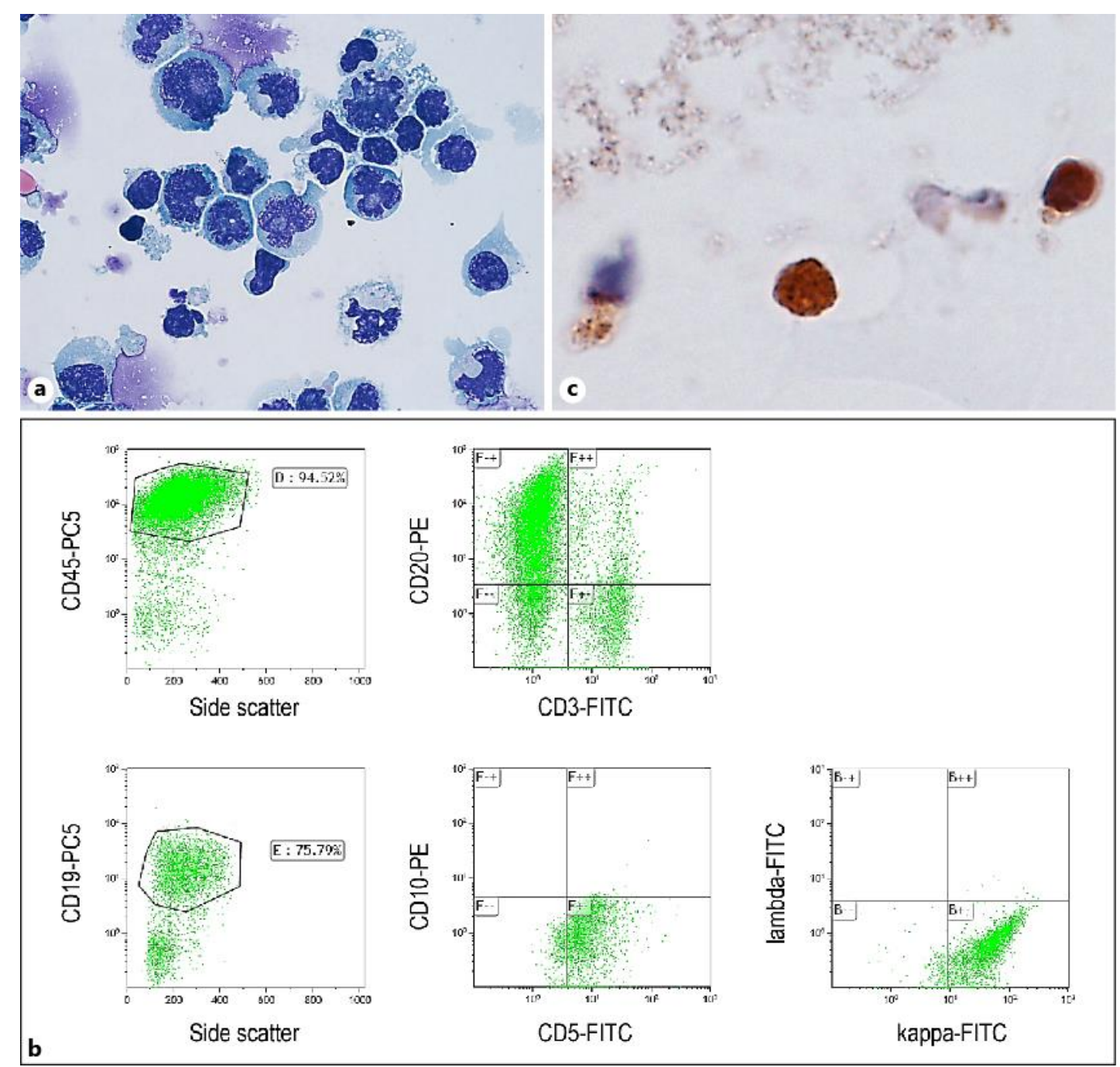

Fig. 2. Morphologic and flow cytometric findings of the vitreous sample. a Morphologic findings of a cytospin specimen of vitreous fluid obtained via vitrectomy. Large abnormal lymphoid cells with irregularshaped nuclei were detected. Giemsa staining. $\times 1,000$. b Flow cytometric analysis revealed that most cells infiltrating the vitreous were positive for CD5, CD19, CD20, and immunoglobulin light-chain kappa. c LMP-1 immunostaining of the vitrectomy cell block. Large lymphoid cells infiltrating the vitreous expressed LMP-1. $\times 1,000$. 